Review

\title{
Aerosol mass spectrometry: An introductory review
}

\author{
David G. Nash ${ }^{\mathrm{a}}$, Tomas Baer ${ }^{\mathrm{a}, *}$, Murray V. Johnston ${ }^{\mathrm{b}, * *}$ \\ ${ }^{a}$ Department of Chemistry, University of North Carolina, Chapel Hill, NC 27599-3290, United States \\ ${ }^{\mathrm{b}}$ Department of Chemistry, University of Delaware, Newark, DE, United States
}

Received 17 July 2006; received in revised form 11 September 2006; accepted 12 September 2006 Available online 17 October 2006

\begin{abstract}
Aerosol mass spectrometry has become an essential tool in monitoring tropospheric aerosols. Various approaches have been developed for analyzing particles that range in size from $10 \mathrm{~nm}$ to $10 \mu \mathrm{m}$ in diameter, and which consist of salts, soot, crustal matter, metals, and organic molecules, often mixed together. This wide variety of particle types has generated an equally wide variety of ionization sources, which include electron impact, laser ionization, laser desorption, chemical ionization, and electron capture ionization. Some instruments are capable of single particle analysis, while others require the collection of an ensemble of particles to obtain sufficient sample for analysis. Most instruments have been designed to ionize and analyze particular classes of compounds (e.g. salts, soot, or organics). This review provides a very broad overview of the aerosol mass spectrometry field and serves as an introduction to the many papers in this issue that deal with details about specific instruments.
\end{abstract}

(C) 2006 Elsevier B.V. All rights reserved.

Keywords: Aerosol; Review; Mass spectrometry; Instrument

\section{Contents}

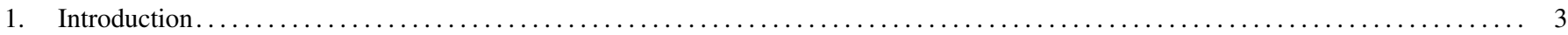

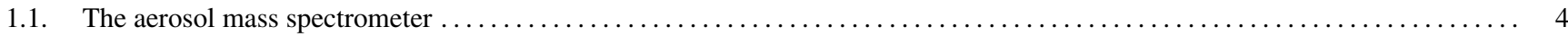

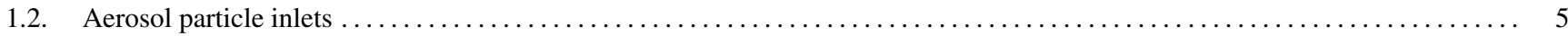

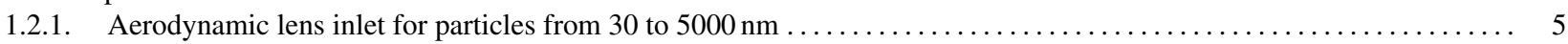

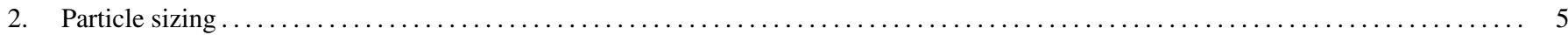

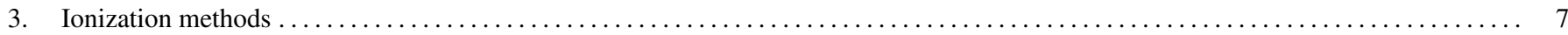

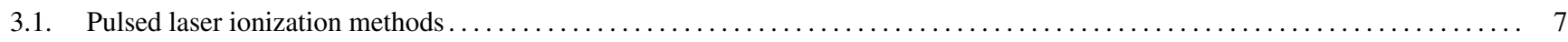

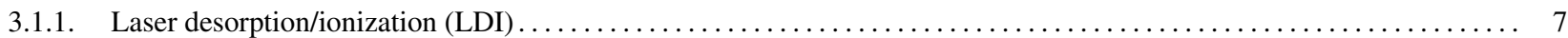

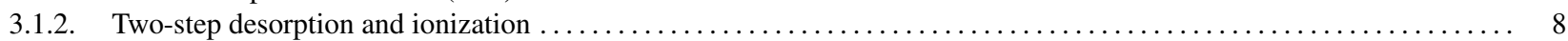

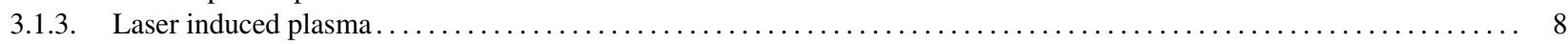

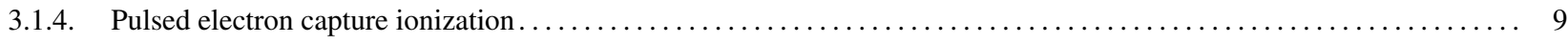

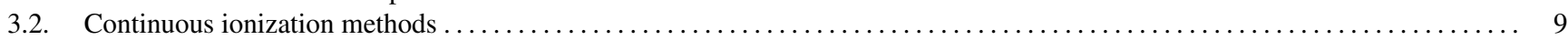

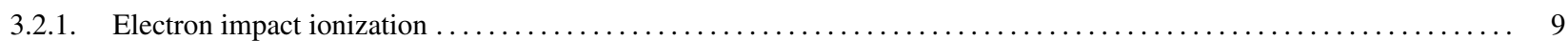

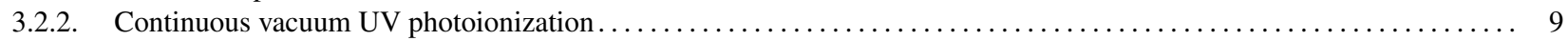

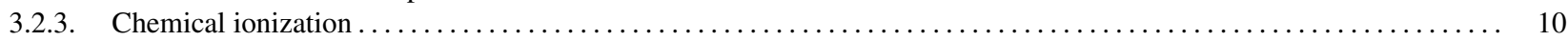

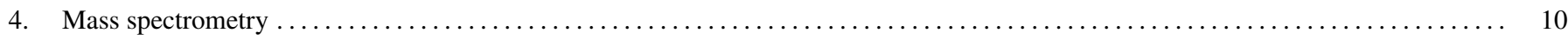

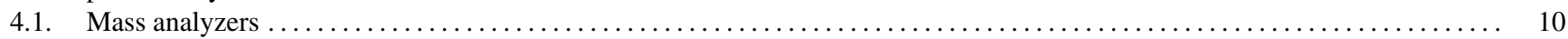

\footnotetext{
* Corresponding author at: Department of Chemistry, University of North Carolina, Chapel Hill, NC 27599-3290, United States. Tel.: +1 919962 1580; fax: +1 9199622388 .

** Corresponding author at: Department of Chemistry, University of North Carolina, Chapel Hill, NC 27599-3290, United States.

E-mail address: baer@unc.edu (T. Baer).
} 


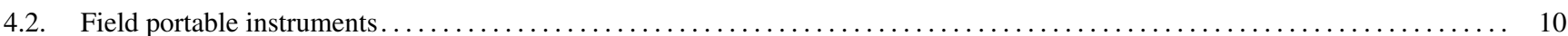

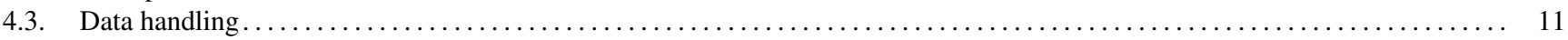

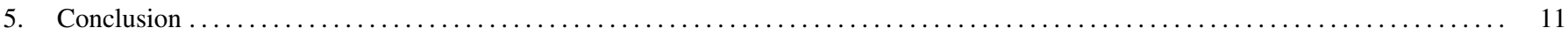

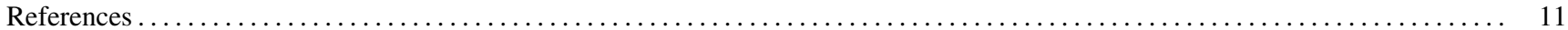

\section{Introduction}

The field of aerosol mass spectrometry has been reviewed in a number of recent articles and the interested reader is encouraged to consult these [1-6]. This article serves as a broad overview to the field as well as an introduction to the papers in this volume. Because readers of this IJMS issue will likely be experts in the field of mass spectrometry, the emphasis here is on various aspects of aerosols, including their transport, light scattering properties, and composition, that affect mass spectrometer design and performance.

The ideal aerosol mass spectrometer should be capable of determining the size of an individual aerosol particle, and provide a quantitative measure of each of its molecular constituents in real time. This is a difficult task because atmospheric particles range in size from less than $10 \mathrm{~nm}$ to greater than $10 \mu \mathrm{m}$, and the molecular constituents are often mixtures that can include sea salt, soot, heavy metals, sand, and a bewildering assortment of organic molecules. The ability to detect individual particles is important in environmental studies where it is essential to know whether particles are uniform mixtures of many constituents (internally mixed), or whether the aerosol is a heterogeneous mixture of various types of particles (heterogeneously mixed). Finally, great benefits accrue if such instruments are portable so that they can be transported to various locations. A number of portable instruments have been developed, and some are commercially available. In this review, we discuss the fundamental issues associated with aerosol mass spectrometry.

The broad distribution of particle sizes poses a number of challenges in aerosol analysis. For instance, a $10 \mu \mathrm{m}$ particle contains about $500 \mathrm{pg}$ of material, which is readily within the range of any mass spectrometer's sensitivity. However, the mass drops by nine orders of magnitude when the diameter is reduced by a factor of 1000 to $10 \mathrm{~nm}$. Molecular identification in single $10 \mathrm{~nm}$ particles is clearly beyond the range of current instruments, although atomic constituent analysis in which multiple atomic ions are produced from each molecule may be possible [7]. Real time mass spectrometry with molecular information in ultrafine particles is possible if an ensemble of particles is analyzed. Other issues include the efficiency of particle introduction into the mass spectrometer, which is readily accomplished with large particles but becomes less efficient with smaller particles.

The distribution of particle sizes in the troposphere is shown in Fig. 1 in the form of three graphs in which the number concentration, the surface area, and the total mass concentrations of a typical urban aerosol are plotted as a function of the particle diameter [8]. Such distributions are generally plotted as $\Delta N / \Delta \log D$ versus $\log D$, where $N$ is the number of particles per unit volume, because the range of sizes from $10 \mathrm{~nm}$ to $10 \mu \mathrm{m}$ spans three orders of magnitude, which would be difficult to plot on a linear scale. The relationship between a standard
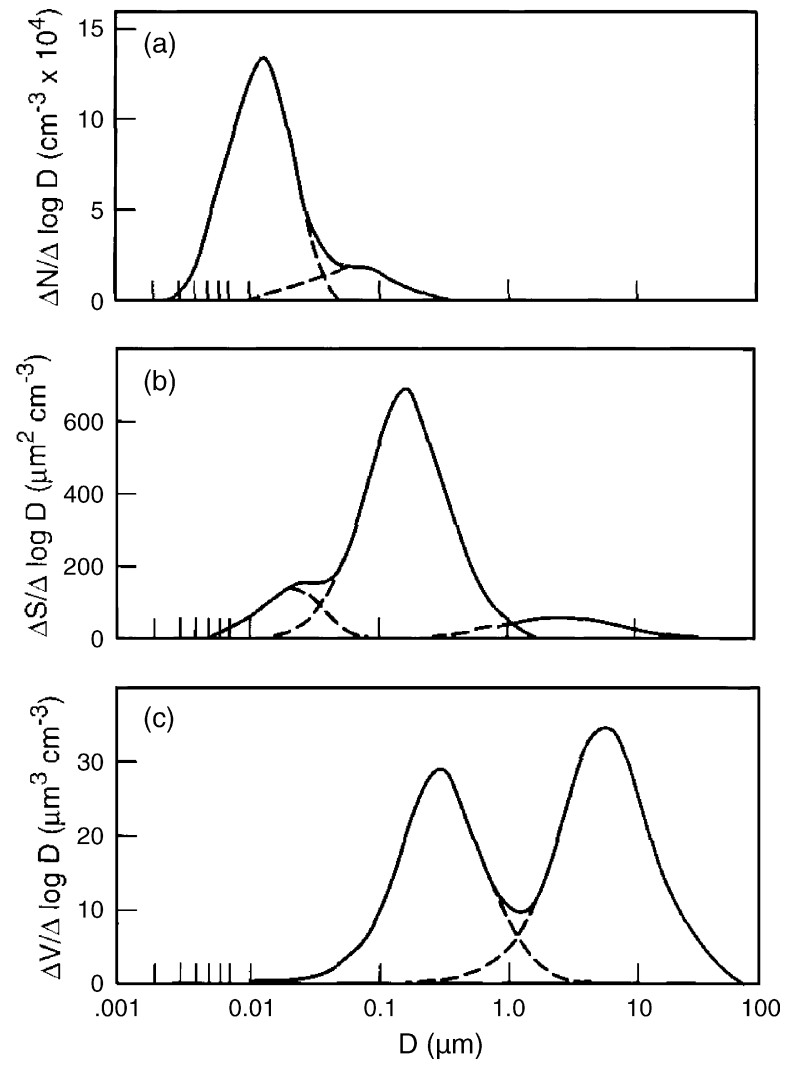

Fig. 1. A typical urban tropospheric aerosol size distribution, taken with permission from Finlayson-Pitts and Pitts [8]. (a) The number density distribution, (b) the surface area distribution, and (c) the volume or mass distribution.

distribution, $N$ versus $D(\Delta N / \Delta D$ versus $D)$ and a logarithmic distribution $(\Delta N / \Delta \log D$ versus $\log D)$, is shown in Fig. 2 . When the distribution plotted on the log scale has the shape of a Gaussian (normal) distribution, we refer to it as a log normal distribution, which is quite a common form for particle size distributions. Returning now to Fig. 1, it is evident that on the basis of number concentration, the smallest or ultrafine particles dominate. In terms of mass or volume, Fig. 1c shows that the fine and coarse (largest) particles dominate. Fig. 1b shows the surface area distribution, in which the fine particles dominate. These three particle size ranges affect human health and the environment in different ways. For instance, the fine and ultrafine particles can be particularly damaging to the lungs because they are easily inhaled into the deepest parts of the lungs, whereas the coarse particles are generally stopped in the nasal passages. Because of their large surface area, the fine particles might be expected to dominate gas-surface reactions in the troposphere. Finally, because light scattering is strongly affected by particle size, the particles' effect on visibility and on the reflection of solar light is also strongly affected by particle size [9]. 


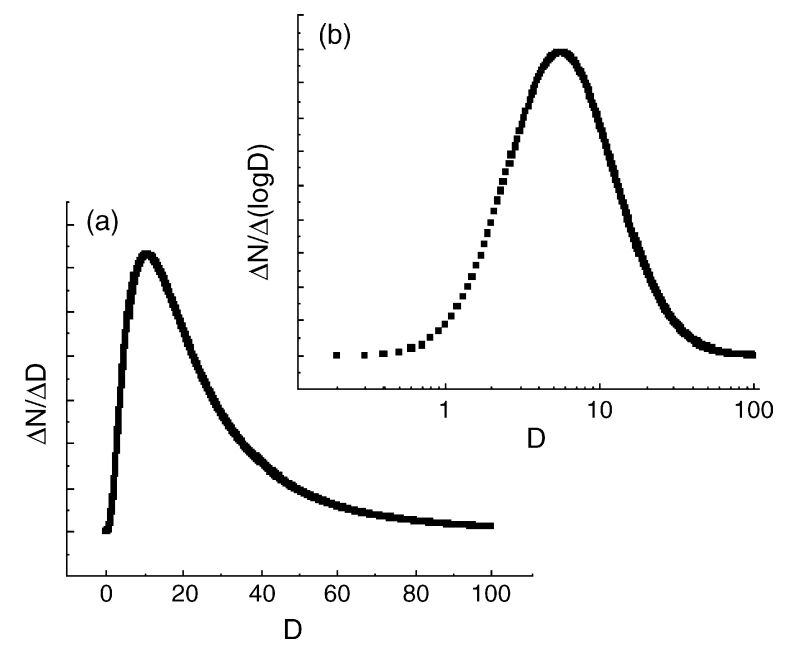

Fig. 2. Comparison of a log normal distribution plotted as a function of the particle diameter and as a function of the log of the diameter. A log normal distribution appears as Gaussian distribution when plotted on the log scale.

The approach to mass spectrometric detection of these particles is dictated by the particle size and mass distribution. When single particle analysis is no longer feasible as a result of their small size, an approach that studies the mass spectrum of an ensemble of particles is still possible, albeit at the expense of single particle information. Most instruments are designed for specific particle size ranges because the ionization scheme as well as data collection approach for single particle and ensemble particle analysis are quite different. In addition, the particle inlet system is generally optimized for specific size ranges, outside of which the transmission degrades significantly.

The second challenge in aerosol mass spectrometry is associated with the mixture of various compounds. Salts are not readily vaporized, and in the early stages of vaporization when the density is high, tend to recombine with oppositely charged ions, thereby making quantification difficult, if not impossible. Organic species include semi-volatile molecules that can vaporize in the aerodynamic inlet system, in which they spend about $30 \mathrm{~ms}$. A similar issue arises with water evaporation in aqueous salt particles. At the other extreme, high mass oligomers are difficult to vaporize and thus may be underestimated. Finally, fragile organics, which are often combined with oligomers, fragment extensively when vaporized and ionized.

Because different molecular species require different methods of vaporization and ionization, it is readily apparent that no single instrument can provide all of the desired information. In the papers that follow, several different instrumental configurations are described, each having its own particular advantage for the intended application. The basic principles underlying instrument design and performance also have "spin-off" applications beyond mass spectrometry. Examples in this issue are the articles by Zhang and Wexler and Agnes and coworkers.

What contributions to the field of aerosol science have been made by direct probing of aerosols with mass spectrometers? The major issues addressed in laboratory based experiments have been in the study of gas surface kinetics in flow tubes. These have included the direct measurements of uptake coef- ficients for ozone reacting with a variety of pure $[10,11,12,13]$ and mixed particles, [11,13,14] including coated particles [15], as well as the reactive uptake of nitric acid into aqueous sodium chloride particles $[16,17]$. In addition, the homogeneous nucleation kinetics and mechanism of ozone and $\alpha$-pinene reaction has provided the first indication of oligomer formation in the early stages of this reaction [18]. Such measurements are essential for modeling the concentration of various organic species in the troposphere. A considerably greater number of publications have resulted from field studies, some of which are contained in this issue.

The major issues addressed in field work make use of the fast measurement capabilities of aerosol mass spectrometers. Aerosol mass spectrometers have made it possible to study the chemical composition of particles as a function of rapid changes in meteorology [19,20], to draw detailed associations between wind direction and particles that are emitted from specific sources [21,22] and to understand the chemical basis for particle nucleation and growth in the atmosphere [23-25]. An aircraft mounted single particle mass spectrometer has been used to determine the composition of particles in the upper troposphere and lower stratosphere [26,27].

Two portable aerosol mass spectrometers are currently commercially available. The aerosol time of flight mass spectrometer (ATOFMS), offered by TSI, is a single particle instrument based on desorption/ionization of single particles by the $266 \mathrm{~nm}$ light from a NdYAG laser. It uses a reflecting time of flight (RETOF) spectrometer for both positive and negative ions that it can collect simultaneously. The other instrument, the aerosol mass spectrometer (AMS), is sold by the Aerodyne Corporation. It focuses on a broader range of particle sizes using the continuous EI ionization method with either a quadrupole mass filter or TOF analyzer.

\subsection{The aerosol mass spectrometer}

A generic diagram of an aerosol mass spectrometer is shown in Fig. 3. The important components are (1) one or more optional aerosol conditioning devices upstream of the mass spectrometer, (2) a particle inlet and differential pumping system where particle sizing is usually performed, (3) a source region where

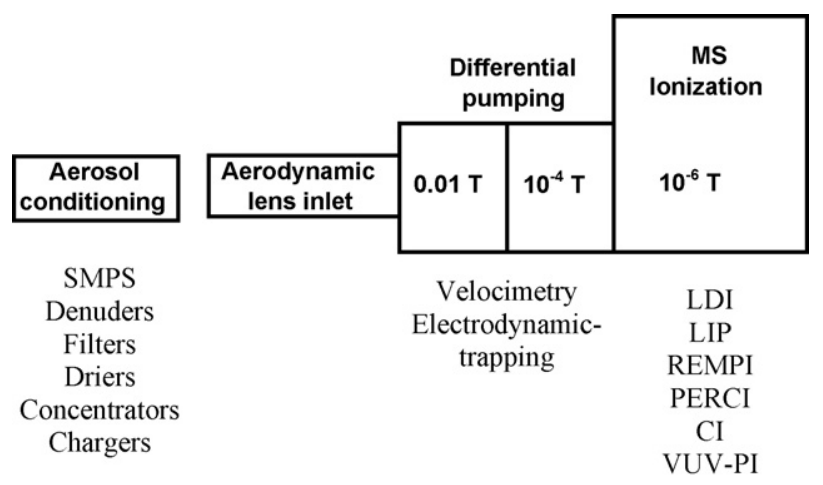

Fig. 3. Block diagram of an aerosol mass spectrometer. The particle inlet and three chambers evacuated by three pumps, $\mathrm{P}_{i} . \mathrm{P}_{1}$ can be either a mechanical pump or a turbomolecular pump. Typical operating pressures (in Torr) are shown. 
particle vaporization and ionization occurs, and (4) a mass analyzer. Essentially all instruments use an aerodynamic lens (to be described) to bring fine and large particles suspended in air into the vacuum system and to direct the particles efficiently toward the ionization region. Because the aerodynamic lens design is particle size dependent, the mass spectrometer must be optimized for specific size ranges already at this early stage of sample introduction. The aerosol sizing approach also depends on the size range of interest and as such is handled differently in different instruments. A final major diversity among various instruments lies in the vaporization/ionization systems in that some instruments use a single laser to accomplish both functions, whereas others separate the two steps. The ionization methods include electron impact, multiphoton ionization, vacuum UV photoionization, electron capture, and chemical ionization. Mass analysis is accomplished primarily by time of flight (TOF), quadrupole mass filters, or quadrupole ion traps.

\subsection{Aerosol particle inlets}

Aerosols are suspended in air by Brownian motion, and are introduced into the mass spectrometer through a nozzle, which can range from 100 to about $200 \mu \mathrm{m}$ in diameter. The nozzle size is limited by a number of factors, the major one being the pumping speed available for portable instruments. The gas flow through a $100 \mu \mathrm{m}$ orifice from atmosphere into a vacuum is $0.1 \mathrm{~L} \mathrm{~atm} / \mathrm{min}\left(1.7 \mathrm{~cm}^{3} \mathrm{~atm} / \mathrm{s}\right)$. A pump with a conductance of $200 \mathrm{~L} / \mathrm{s}$ can thus maintain a pressure of $6 \times 10^{-3}$ Torr in the first region of the differential pumping system.

The number of particles entering through this inlet nozzle can be determined from the particle number density. Thus a particle density of $10^{3}$ particles $/ \mathrm{cm}^{3}$ would result in the introduction of 1700 particles/s into the inlet system. If only the total particulate mass is of interest, we need to consider the mass density, which can range from 1 to $100 \mu \mathrm{g} / \mathrm{m}^{3}$, the former corresponding to very clean air [8]. A typical density of $30 \mu \mathrm{g} / \mathrm{m}^{3}$ will inject about $3 \times 10^{-11} \mathrm{~g} / \mathrm{s}$ or $30 \mathrm{pg} / \mathrm{s}$ of material into the MS.

\subsubsection{Aerodynamic lens inlet for particles from 30 to $5000 \mathrm{~nm}$}

A critical component in aerosol mass spectrometers is the sample introduction system. The introduction of just $30 \mathrm{pg} / \mathrm{s}$ of material is sufficiently small to require a very efficient particle transport system from the $100 \mu \mathrm{m}$ orifice to the ionization region. Ten years ago, McMurry and co-workers developed an aerosol inlet, a so-called aerodynamic lens, which consists of a $100 \mu \mathrm{m}$ flow limiting orifice attached to a $1 \mathrm{~cm}$ inner diameter, $30 \mathrm{~cm}$ long tube [28,29]. A series of carefully designed and machined apertures gently force the particles to the center of the tube by the time they reach the end of the lens where a $2 \mathrm{~mm}$ nozzle accelerates the particles into the vacuum (Fig. 3). The apertures can be designed to pass only particles of a particular size, or a range of sizes, and a recent article from the McMurry group provides prescriptions and a program for a lens design for specific particle size ranges [30-32]. The particles inside the aerodynamic lens, where the pressure is approximately 2 Torr, are still suspended by Brownian motion and thus travel at the average gas flow speed of about $8 \mathrm{~m} / \mathrm{s}$. However, as they pass through the $2 \mathrm{~mm}$ expansion nozzle into a pressure of .01 Torr, they are accelerated by numerous gas-particle collisions to a final speed of between 50 and $200 \mathrm{~m} / \mathrm{s}$. Because the lens focuses the particles into the middle of the exit nozzle, and because of the statistically very large number of collisions, the net force exerted on the particle is very much forward directed so that the particle beam exiting the nozzle has a very low divergence, which is ideal for transporting the particle to the ionization region. It has been estimated that the $90 \%$ of spherical particles with a diameter of $500 \mathrm{~nm}$ that enter the $100 \mu \mathrm{m}$ nozzle are transported to the center of the ionization region [33]. However, the divergence of the particle beam increases dramatically as the particles become smaller and is the major reason for decreasing transmission of particles below $100 \mathrm{~nm}$ [34]. Zelenyuk and Imre [35] recently optimized their system, which permits them to detect particles down to $50 \mathrm{~nm}$, and TSI advertises transmission of their ATOFMS instrument inlet system from 30 to $300 \mathrm{~nm}$. Johnston and co-workers found that they could focus charged particles $<50 \mathrm{~nm}$ in diameter using an electrostatic field [36] and $<10 \mathrm{~nm}$ in diameter using an electrodynamic field [37]. An article in this issue by Johnston and co-workers describes a system for electrodynamic focusing and trapping of particles below $30 \mathrm{~nm}$. An article in this issue by McMurry and coworkers details an aerodynamic lens that can pass particles $3-30 \mathrm{~nm}$ in diameter with $50-80 \%$ efficiency, respectively. This is particularly important in that it helps to bridge the gap between particles less than $3 \mathrm{~nm}$ in diameter which can only be focused using electrodynamic lenses, and particles tens of nanometers and larger which are difficult to focus with electrodynamics due to the high required voltages.

Fluid dynamic calculations for aerodynamic lens operation are based on spherical particles. Non-spherical trajectories, which are difficult to calculate, can deviate substantially from spherical ones so that the focusing of such particles becomes less efficient.

\section{Particle sizing}

The geometric diameter of an aerosol particle can be determined from an SEM image. However, on-line determinations that depend on indirect methods such as light scattering, diffusion, or sedimentation rates, are sensitive to both the geometric or physical diameter, $D$, as well as the particle's density, $\rho$. The relationship among the various definitions of particle sizes for spherical as well as non-spherical particles has been reviewed and quantified by deCarlo et al. [38].

Particle sizing outside the mass spectrometer can be accomplished by various methods depending on particle size. Particles with diameters in excess of $3 \mathrm{~nm}$ can be size selected by differential mobility analyzers (DMA) in which particles suspended in air by Brownian motion, are electrically charged and pass through an inhomogeneous electrical field, much like a cylindrical mirror electrostatic analyzer. In the DMA the collisional 
drag force is balanced against the electric field force, which makes this measurement for spherical particles proportional to the physical diameter, $D$. Such DMA's can be placed in front of the MS inlet nozzle to pre-select the particle size. The addition of a particle counter permits collection of a particle size distribution.

Two kinds of aerodynamic diameters are commonly used. When a particle is allowed to drift vertically through a gas by the earth's gravitational force, its terminal velocity will be related to its aerodynamic diameter, $d_{\mathrm{a}}$, which for spherical particles is equal to $D\left(\rho / \rho_{0}\right)^{1 / 2}$, where the $\rho$ 's are the particle density and standard density of $1 \mathrm{~g} / \mathrm{cm}^{3}$, respectively. For non-spherical particles, a volume equivalent diameter, $d_{\mathrm{ve}}$, can be defined such that $d_{\mathrm{ve}}=(6 V / \pi)^{1 / 3}$, where $V$ is the physical volume of the particle. Particles with diameters in excess of $30 \mathrm{~nm}$ can also be size selected in the mass spectrometer by measuring their terminal velocity with which they exit the aerodynamic lens. This vacuum aerodynamic diameter, $d_{\mathrm{va}}$, differs from the $d_{\mathrm{a}}$ because the particles are accelerated from a pressure of 1-2 Torr in the aerodynamic lens into the first stage of the differential pumping region, which has a pressure of about $10^{-2}$ Torr. The latter is in the molecular flow regime in which collisions between particles and gas are essentially stopped. The result is that the vacuum aerodynamic diameter for spherical particles is given by $d_{\mathrm{va}}=D\left(\rho / \rho_{0}\right)$. Because of this dependence on the density, it is possible to measure simultaneously the geometric diameter and the particle density by measuring both the geometric diameter by a DMA and the vacuum aerodynamic diameter by velocimetry [15].

The terminal velocities of the aerosol particles exiting the aerodynamic lens have been fitted to the empirical Eq. (1) proposed by Jayne et al. [39]:

$v=\frac{v_{\mathrm{g}}}{1+\left(d_{\mathrm{va}} / d^{*}\right)^{b}}$

where $d_{\mathrm{va}}$ is again the vacuum aerodynamic diameter, $v$ the particle velocity, $v_{\mathrm{g}}$ the molecular velocity of the jet expansion, and $d^{*}$ and $b$ are fitted coefficients. $d^{*}$ represents the characteristic diameter for particle expansion from the aerodynamic lens. In the Jayne study, $d^{*}=27.2 \pm 0.5 \mathrm{~nm}$, and $b=0.479 \pm 0.004$. The velocity of the gas, $v_{\mathrm{g}}$, can be obtained from the expansion enthalpy of (5/2)RT and the molecular weight of the gas, which for air at $298 \mathrm{~K}$ yields a velocity of about $600 \mathrm{~m} / \mathrm{s}$. An example of the particle transit time between two light scattering stations for particles of various sizes is shown in the article by Cziczo et al. in this special issue. This plot of $v$ versus the aerodynamic diameter was created with particles of various densities, but plotted as function of their vacuum aerodynamic diameter, $D \rho$, discussed above. This variation of velocity with particle size continues down to quite small particles, but eventually, when the particles diminish in size to $1 \mathrm{~nm}$, their final velocity approaches the terminal beam velocity of the gas and thus becomes independent of particle size.

The particle velocity can be measured in two ways. The Aerodyne MS instrument, described in paper by Schneider et al. and Schneider et al. in this issue, uses a chopper wheel that selects clumps of particles and uses the arrival of ions at the detec- tor to determine the velocity and thereby the particle size [39]. Because the flight time of the particles from the chopper wheel to the ionization region is on the order of a millisecond, and the ion TOF in the mass analyzer is tens of $\mu s$, the ion transit time is negligible compared to the particle flight time. This approach to velocity measurement is applicable to a very broad range of particle sizes, and is not limited to single particle analysis. In fact, its virtue lies in its ability to size large fluxes of small particles, for which single particle MS is in any case not possible. The major shortcoming is the small duty cycle (1.8\%) of the chopper wheel.

The other in situ method for particle velocity determination is based on measuring the transit time of particles as they pass through two continuous laser beams that are separated by approximately $10 \mathrm{~cm}$. The light scattered by the single particles as they pass through the beam is monitored by photomultipliers. Green diode lasers at $532 \mathrm{~nm}$ are preferred over the red HeNe lasers $(632.8 \mathrm{~nm})$ because they scatter light more efficiently and their light is detected with greater sensitivity by the photomultipliers. This method is applicable to small fluxes of larger particles for which single particle MS is possible. The effect of particle shape on its terminal velocity is an interesting one that has been investigated recently by Zelenyuk et al. [40].

The light scattering is strongly dependent on particle size, the wavelength of the light, as well as the scattering angle. In the Rayleigh limit, where the particles are much smaller than the wavelength of the light, the scattering intensity is proportional to $D^{6}$, where $D$ is the particle diameter. This strong dependence of the scattering intensity on the particle diameter means that light scattering is limited to particles with a diameter greater than about $100 \mathrm{~nm}$. However, light scattering has recently been reported for smaller particles using short wavelength light generated by synchrotron radiation [41]. Because of the diminished scattering intensity of small particles, recent innovations that maximize the collected light include the use of elliptical mirrors that collect the full $4 \pi$ solid angle of scattered light $[34,35]$. One focal point is the intersection of the particle and laser beams, and the PMT is placed at the other focal point.

Although the scattering intensity varies rather smoothly with scattering angle for small particles, [42] the functional form becomes more complicated with large particles because the light is internally reflected in the particle. Fig. 4 shows scattering intensity versus scattering angle for three different sized particles as represented by the size parameter $\alpha$, where

$\alpha=\frac{\pi d_{\mathrm{p}}}{\lambda}$

The interference effects evident for the large particles, which can be modeled with Mie theory, [42] yield an intensity pattern that varies strongly with the scattering angle. Such angular distributions have been used to determine very precise diameters for spherical particles [43-45]. However, the measurement of angular distributions is complicated and does not lend itself for use in mass spectrometric analysis of particles. In addition, the scattering is much more complex for non-spherical particles. The more easily accomplished alternative, to measure the light 


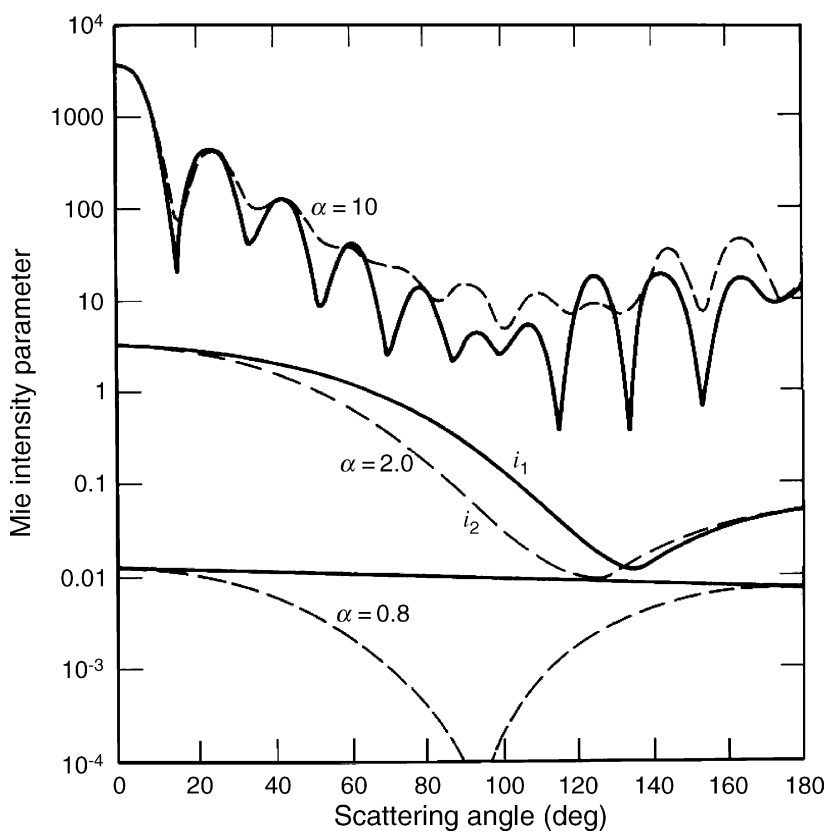

Fig. 4. Light scattering as a function of angle for various values of $\alpha$ taken with permission from Hinds [95]. For a photon wavelength of $532 \mathrm{~nm}$, the three value of $\alpha(10,2$ and 0.8$)$ correspond to particle diameters of $1.7 \mu \mathrm{m}, 338 \mathrm{~nm}$, and $135 \mathrm{~nm}$, respectively.

intensity at a single angle, is not reliable, as shown by Salt et al. [46].

\section{Ionization methods}

The method of ionization employed in aerosol MS must be matched to the types of aerosol particles. A $10-20 \mathrm{~Hz}$ pulsed laser can be used to desorb/ionize particles that enter the MS at rates less than 20 times per second. They require that the laser be pulsed at random times when the light scattering station indicates the arrival of a particle in the ionization region. Electronic units to manage the pulsing requirements for various lasers, in particular Nd:YAG lasers whose flash lamps must be pulsed some $250 \mu$ s prior to the laser pulse, have been described $[47,48]$. Although such low frequency pulsed lasers would not be efficient in ionizing the smaller particles that enter the MS at the rate of 1000 per second or more, the use of a $1 \mathrm{kHz}$ excimer laser would appear to be an attractive option. However, the latter has not been reported in aerosol MS work. In general, a more efficient approach for quasi-continuous arrival times of small particles (as shown in Fig. 1, the ultrafine particles are much more numerous than the large particles) is the use of a continuous ionization method such as electron impact or chemical ionization.

The chemical composition of the particle also plays a role in the choice of ionization methods. Salts, metals, and crustal particles are most efficiently desorbed and ionized by a strong UV laser pulse, whereas the more easily vaporized organic molecules are better ionized by electron impact, chemical ionization, electron attachment, or one-photon vacuum UV ionization. All of these methods are described in the various papers in this issue.

\subsection{Pulsed laser ionization methods}

\subsubsection{Laser desorption/ionization (LDI)}

Johnston and Murphy were among the first to couple laser desorption/ionization (LDI) with time-of-flight mass spectrometry in the early 1990s [49,50]. Particles were detected by monitoring light scattering signal from a single $\mathrm{HeNe}$ laser passing through the ionization region, similar to the method developed by Sinha [51]. The photomultiplier signal triggered an excimer laser $(193 \mathrm{~nm})$ that desorbed and ionized the single aerosol particles. The single HeNe light scattering station located in the ionization region, did not permit sizing of the particles, but rather was used simply to signal the arrival of a particle in the ionization region. This arrangement is possible with excimer and nitrogen lasers that can be triggered within a few $100 \mathrm{~ns}$, during which time particles move less than $100 \mu \mathrm{m}$.

The LDI method is extremely sensitive because a very large number of photons (ca $10^{16}$ per pulse) can be directed at a particle that is known to be in the ionization region. In principle, every laser shot should generate a large flux of ions. Single particles with diameters as small as $50 \mathrm{~nm}$ and below have been detected with good signal to noise $[35,52,53]$. This sensitivity is probably limited to salt particles in which the existing ions need only be desorbed as opposed to organics where both vaporization and ionization are required to obtain an ion signal.

In 1994, Prather et al. [48] used LDI with the fourth harmonic of a Nd:YAG laser at $266 \mathrm{~nm}$. As mentioned above, the flash lamps of this laser must be triggered about $250 \mu$ s prior to firing the Q-switch (which triggers the laser light pulse) so that the light scattering station must be located approximately $10 \mathrm{~cm}$ from the ionization region. In other words, the laser must be triggered well before the particle reaches the ionization region.

The UV laser desorption/ionization approach is ideal for particle sizes in excess of about $50 \mathrm{~nm}$ and for measuring salt and metal containing particles, which are indeed difficult to ionize by other methods. Although particles smaller than $50 \mathrm{~nm}$ can be analyzed, the ion signal decreases with decreasing particle mass and it becomes difficult to distinguish the signal from background. UV laser desorption/ionization is less useful for organic species because of the considerable fragmentation induced. This is a result of the high laser intensity required to desorb and ionize the particle. Any organic ions generated will readily absorb multiple UV photons resulting in massive fragmentation. However, certain mass fragments, such as 37,39 , and 41 are useful markers for the presence of organic species with different functionalities in the particles [54]. A class of molecules that often yields significant parent ion signal are aromatic hydrocarbons because they tend to be rather stable ions and because they are readily ionized by a resonant $1+1$ laser absorption scheme [55]. Fig. 2 in the article by Bente et al. in this issue shows examples of such spectra. It is possible to manipulate the desorption/ionization process to enhance the formation of molecular ions. For example, in this issue Prather and coworkers describe the use of a lower pulse energy laser beam to decrease the amount of fragmentation. Also in this issue, Reilly and coworkers describe a system to coat particles entering the mass spectrometer with a 
matrix that promotes large ion formation by matrix-assisted laser desorption ionization.

One of the problems in quantitative determinations of salt and metal containing particles by laser desorption/ionization is matrix effects [56,57]. The high concentration of positive and negative ions generated by the laser pulse impinging on a $1 \mu \mathrm{m}$ particle, leads to ion-ion recombination reactions that deplete the signal. Indeed, Dessiaterik et al. [58] demonstrated that for low ion concentrations $\mathrm{RbCl}$ in a solution of ethylene glycol, the observed ion signal is linear with the concentration, whereas it levels off at concentrations in excess of $10^{-4} \mathrm{M}$, and becomes completely insensitive to the ion concentration above $10^{-3} \mathrm{M}$. Although absolute quantitation under these circumstances is clearly not possible, relative yields among similar particles are still useful.

\subsubsection{Two-step desorption and ionization}

Gas-phase ionization methods can be used for aerosol analysis if they are coupled with a separate thermal or laser desorption step. Several configurations are described below.

\subsubsection{Resonance enhanced multi-photon ionization} (REMPI). Multiphoton ionization can occur by a non-resonant simultaneous absorption of several photons. The greater the number of photons involved, the more tightly the laser must be focused in order to drive the transition. The cross section is approximately related to $I^{n}$, where $I$ is the laser intensity and $n$ the number of photons absorbed in the non-resonant step. If the molecule has a real electronic state at an energy that is a multiple of the photon energy, the cross section increases significantly, and is termed resonance enhanced multiphoton ionization, or REMPI. In general, REMPI is not a very useful approach for aerosol mass spectrometry because, (a) the particle beam can easily be missed by the tightly focused laser beam, and (b) the ion signal intensity can vary by orders of magnitude from one molecule to another. The one exception is a 1:1 two-photon absorption in which the laser does not have to be focused because the absorption does not involve any non-resonant steps so that the process becomes linear. That is, the ion signal intensity obtained by 1:1 photoionization of a diffuse sample is independent of the laser focal volume. This ionization method is applicable primarily to aromatic molecules because the benzene ring has a strong absorption around $266 \mathrm{~nm}(4.66 \mathrm{eV})$, which lies more than half way to the ionization limit of aromatic molecules (generally about $9 \mathrm{eV}$ ). In this issue, Zimmermann and coworkers discuss the relative merits of LDI and thermal desorption - REMPI for the analysis of organic particles.

3.1.2.2. Vacuum $U V(V U V)$ ionization. In order to overcome the limitations of UV laser desorption/ionization for speciating the organic fraction of aerosol particles, Baer and Miller introduced vacuum UV photoionization in conjunction with a prior vaporization step [59]. An IR laser, $\left(\mathrm{CO}_{2}\right.$ at $10.2 \mu \mathrm{m}$ or a tunable OPO in the $3 \mu \mathrm{m}$ region) was used to gently vaporize the particles consisting of organic species. The VUV laser, triggered several $\mu \mathrm{s}$ later, ionized a low density plume of gas phase species, which eliminated the matrix effects caused by ion molecule reactions in high density samples. The fragmentation is reduced because the high intensity UV laser is replaced with a low intensity VUV laser pulse, which can ionize the sample gas with single photon absorption, thereby eliminating multi-photon processes. This approach is limited to particles above about $300 \mathrm{~nm}$ since the particle mass must be above the detection limit. Johnston and co-workers extended the VUV ionization method to particles of arbitrary size by collecting the particles on a cold finger. After a sufficient number of particles are deposited, the sample is flash vaporized with an IR laser, followed by photoionization with the VUV laser pulse [60].

Coherent VUV radiation can be generated by two methods. A particularly convenient approach is 3rd harmonic generation using the $355 \mathrm{~nm} \mathrm{Nd}$ :YAG laser pulse directed into a cell containing about 14 Torr of Xe diluted with 165 Torr of Ar for phase matching purposes [61]. Three $355 \mathrm{~nm}$ photons directed into the sample are converted into one $118 \mathrm{~nm}$ photon $(10.5 \mathrm{eV})$ by a coherent process that requires a focused $\mathrm{Nd}$ :YAG laser with about $10-20 \mathrm{~mJ}$ of pulse energy. This process, which has an efficiency of about $10^{-7}$, generates approximately $10^{10} \mathrm{VUV}$ photons per pulse [62]. Given a typical absorption cross section of $10^{-18} \mathrm{~cm}^{2}$, it is evident that only about 1 in $10^{7}$ molecules will be ionized. This limits the VUV laser approach to particle diameters greater than about $300 \mathrm{~nm}$. In general, the detection limit for VUV photoionization of a given molecule is on the order of $100 \mathrm{ng} / \mathrm{m}^{3}$, which does not make it a very competitive method for detecting real tropospheric aerosols, whose mass density can be as low as $1 \mathrm{ng} / \mathrm{m}^{3}$. However, it is very useful for laboratory studies where the particle densities can be raised.

A more general method for VUV photon generation is by twocolor four wave mixing. [62,63] A convenient scheme involves the 2-photon excitation of the $\mathrm{Kr}^{2} \mathrm{P}_{3 / 2}$ state [64] with a pulse of $\lambda_{1}=212.5 \mathrm{~nm}$ light and a simultaneous pulse of tunable visible light $\left(\lambda_{2}\right)$. Sum and difference mixing results in the production of $\lambda_{3}{ }^{-1}=\lambda_{1}{ }^{-1} \pm \lambda_{2}{ }^{-1}$. Although this approach is more complicated, requiring two laser photons that have to be carefully aligned, the output is a tunable and more intense because it involves only a non-resonant two photon process rather than a coherent three photon process as in third harmonic generation.

Although photoionization by VUV photons dramatically reduces ion fragmentation $[63,65]$, it is not yet clear how effective VUV photoionization is for identifying molecular constituents in tropospheric particles. The $10.5 \mathrm{eV}$ photoionization mass spectra of the $\alpha$-pinene ozonolysis products reported by Tolocka et al. indicate that the reduction in fragmentation over electron impact is significant, but not sufficiently dramatic to permit the identification of more than a few of the reaction products [66]. A two-dimensional approach such as provided by thermal desorption MS [67] coupled with photoionization and high mass resolution MS will be needed to identify the many products in these particles.

\subsubsection{Laser induced plasma}

Originally demonstrated by Reents $[7,68]$ and subsequently Zachariah $[69,70]$, formation of a laser induced plasma is similar to LDI except that a much higher laser irradiance is used. Whereas a few millijoules of ultraviolet radiation are moderately 
focused in the mass spectrometer source region to perform LDI, formation of a laser induced plasma requires tight focusing of a $>100 \mathrm{~mJ}$ pulse, typically from a Nd:YAG laser operating at $532 \mathrm{~nm}$. Under these conditions, the "complete ionization limit" is thought be achieved, where the particle is assumed to be completely disintegrated to atoms and the atoms quantitatively converted to positively charged ions. The positive ion spectrum shows a series of singly and multiply charged ions for each element in the particle. The negative ion spectrum shows only electrons. An advantage of the complete ionization limit is that the combined signal intensities of the series of ions for each element give a semi-quantitative measure of atomic composition. The article by Zachariah and co-workers in this issue discusses quantitative measurements by the laser induced plasma method. Another article by Wang and Johnston describes its use in the characterization of particles in the low nanometer size range.

\subsubsection{Pulsed electron capture ionization}

The capture of low energy electrons as a soft ionization method has been used by mass spectrometrists for many years [71,72,54]. Petrucci and co-workers have developed a photoelectron resonance capture ionization (PERCI) version for use in aerosol mass spectrometry, $[73,74]$ and more recent developments are outlined in another Petrucci article in this journal. Although electron capture ionization is not by its nature a pulsed method, Petrucci employs a $10 \mathrm{~Hz}$, tunable (235-300 nm) UV laser focused onto the surface of an aluminum photocathode to generate low-energy and more or less mono-energetic electrons in a pulsed manner. Given the work function of the $\mathrm{Al}$ metal, the photoelectrons are generated in a range of energies from 0.05 to $1.20 \mathrm{eV}$, which is a convenient range for efficient electron capture ionization.

The electron attachment process generally involves the loss of a hydrogen atom so that the resulting negative ion is closed shell, thereby imparting significant stability. The softness of the PERCI technique is demonstrated in the article by Petrucci in this issue.

\subsection{Continuous ionization methods}

\subsubsection{Electron impact ionization}

Electron impact (EI) is a universal ionization method that has two important attributes. One of these is that a large body of standard spectra collected with $70 \mathrm{eV}$ electrons is available in the literature. This permits the establishment of search routines that can readily identify a compound based on its mass spectrum. For this purpose, it is essential that the MS for a molecule consists of multiple fragment ion peaks that provide a fingerprint for that molecule. The other virtue is that the total integrated intensity of the spectrum for a given molecule is proportional to its pressure in the ionization source. That is, the peak intensities can be quantitatively related to the molecule's concentration. The total intensity is approximately proportional to the total number of electrons in the molecule. This property is not shared with photoionization at a given photon energy because of numerous resonances throughout the molecule's photoabsorption spectrum.

EI has been adopted by the Aerodyne AMS instrument because of the above features. However, tropospheric particles often contain a bewildering number of molecules that cannot be distinguished by an EI spectrum because of the numerous fragment ion peaks. Nonetheless, an article by Schneider et al. in this issue show that basic information about organic composition can be extracted. More detailed molecular information requires multi-dimensional approaches. Although such information can be obtained in the laboratory by methods such as GC/MS or LC/MS that separate the molecules prior to introduction into the mass spectrometer, no "real-time" aerosol mass spectrometer has managed to achieve this. One step in that direction was pioneered by Ziemann and co-workers, who collect the particles on a cold finger. Subsequent programmed thermal desorption releases the molecules from the probe in order of their decreasing volatility, thereby providing a crude pre-separation of the sample prior to ionization and mass analysis [75,76]. Because this important technique is not represented in any of the papers in this issue, we show an example of some thermal desorption data in Fig. 5.

\subsubsection{Continuous vacuum UV photoionization}

Synchrotron radiation, which produces a flux of vacuum UV photons in excess of $10^{15}$ photons/s, has recently been used to photoionize molecules from aerosol particles vaporized by a resistively heated filament [65]. The photon beam generated by the undulator is extremely collimated, and can be focused by grazing incidence mirrors to a spot size of $100 \mu \mathrm{m} \times 200 \mu \mathrm{m}$,

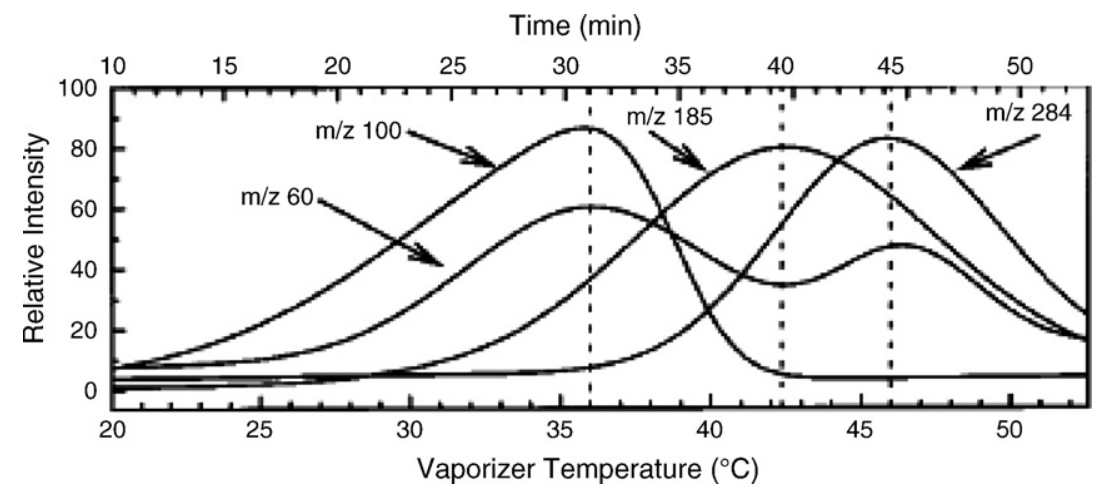

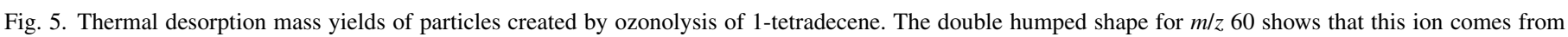
both a low-volatile as well as a more highly volatile reaction product. Taken with permission from Tobias and Ziemann [67]. 
which is an ideal source for time of flight analysis. Synchrotron light also has the advantage of easy tunability, so that the photon energy can be chosen to minimize the ion fragmentation. A detailed description is provided in the article by Wilson et al. in this issue. The major disadvantage of this source is that the experiment must be transported to the synchrotron, and is therefore limited to laboratory based experiments.

\subsubsection{Chemical ionization}

Chemical ionization (CI) is a sensitive and gentle method of ion formation that generally produces only a single mass ion. A very useful reaction is proton transfer, which generates the $M+1$ ion. Common reagents used for proton transfer include protonated water clusters, $\mathrm{H}^{+}\left(\mathrm{H}_{2} \mathrm{O}\right)_{2}$, and protonated methanol clusters, $\mathrm{H}^{+}\left(\mathrm{CH}_{3} \mathrm{OH}\right)_{2}$. The major difference between EI and PI on the one hand, and CI on the other, is that the latter produces closed shell ions, whereas the standard ionization processes generate open shell radical cations that are often unstable. Because many of the molecules found in tropospheric aerosols are quite fragile, soft CI would appear to be an ideal choice for instruments designed to detect the organic fraction of the aerosol particles $[13,77]$. As the paper by Hearn and Smith in this issue demonstrates, the sensitivity for oleic acid detection is on the order of $\sim 200 \mathrm{ng} / \mathrm{m}^{3}$ which corresponds to $\sim 4 \times 10^{8}$ molecules $/ \mathrm{cm}^{3}$ $(\sim 0.02 \mathrm{ppb})$ in gas-phase units. Because many organic particulates in the troposphere contain organic molecules at a concentration of $1 \mathrm{ng} / \mathrm{m}^{3}$, it is not clear that CI will be competitive with EI for ambient measurements.

CI has also been used by Lazar et al. [78] in a pulsed mode by reacting $\mathrm{K}^{+}$ions, produced by a pulsed excimer laser, with the vaporized aerosol sample. Another CI based instrument (TDCIMS) developed by Smith and co-workers, [24,79,80] is designed to analyze particles down to $10 \mathrm{~nm}$. Ambient aerosol particles are charged in a unipolar aerosol charger and drawn into the TDCIMS instrument. They are then collected by an electrostatic precipitator for $6 \mathrm{~min}$, desorbed by resistively heating the collection wire, and finally ionized via chemical ionization.

\section{Mass spectrometry}

\subsection{Mass analyzers}

The three major methods of mass analysis in aerosol mass spectrometers have been time of flight (TOF) and RETOF, quadrupole mass filter, and the quadrupole ion trap. The two major commercial instruments use an ion RETOF (TSI) and a quadrupole (Aerodyne). Of these, only the TOF and the ion trap instruments can be used as a true single particle mass spectrometer. In addition, the dual TOF arrangement of the TSI instrument is capable of collecting both positive and negative ion mass spectra, which is highly useful in the analysis of salt particles [81]. As shown by Reilly et al. $[82,83]$ when the ion trap is operated in the mass selective instability mode, the RF voltage on the ring electrode is ramped, ejecting ions sequentially so that all of the ions can be detected, thereby permitting single particle detection.
The ion trap can also be used for MS/MS studies [83]. In principle, MS/MS provides information about the structure of a targeted mass peak in the mass spectrum, and thus could lead to the identification of a compound in the aerosol particle. On the other hand, difficulties in real-time data-dependent selection of precursor ions for MS/MS analysis and the need for manual interpretation of complex product ion spectra may inhibit its use in the field.

Because of the large number of molecular organic constituents in tropospheric particles, any given nominal mass peak most likely consists of several compounds. For instance, the $m / z, 98$ peak can be attributed to $\mathrm{C}_{7} \mathrm{H}_{14}, \mathrm{C}_{6} \mathrm{H}_{10} \mathrm{O}, \mathrm{C}_{5} \mathrm{H}_{6} \mathrm{O}_{2}$, or $\mathrm{C}_{4} \mathrm{H}_{2} \mathrm{O}_{3}$. These can be readily resolved by high resolution MS. Because the oxygen content of the peaks provide important information about the aerosol origin and its secondary reactions in the troposphere, this information is highly valuable. In the laboratory, several options for high resolution MS are available. Fewer options exist for field measurements. The installation of an orthogonal RETOF mass analyzer may provide sufficient resolution to obtain such information for relatively low $\mathrm{m} / \mathrm{z}$ ions, for example $\mathrm{C}_{3} \mathrm{H}_{7}{ }^{+}$and $\mathrm{C}_{2} \mathrm{H}_{3} \mathrm{O}^{+}$at a nominal $\mathrm{m} / z$ of 43 [84].

\subsection{Field portable instruments}

A major thrust in aerosol mass spectrometry has been the development of field portable instruments. Several EPA supersites have invited researchers with a variety of instruments in one location in order to collect atmospheric data for up to 2 years [85]. The types of measurements conducted have included data on wind direction and velocity, pollutant levels (ozone, $\mathrm{CO}$, $\mathrm{CO}_{2}, \mathrm{NO}_{x}$, etc.), relative humidity, and particulate matter. In the 1999 Atlanta supersite study, four aerosol mass spectrometers were operated simultaneously, and a study comparing the results was published [85]. The instruments in question were NOAA's particle analysis by laser mass spectrometer (PALMS), University of California at Riverside's Aerosol Time-of-Flight Mass Spectrometer (ATOFMS) [86], University of Delaware's Rapid Single-Particle Mass Spectrometer (RSMS), and Aerodyne's Aerosol Mass Spectrometer (AMS). These instruments differed in their ionization methods (laser desorption/ionization for the PALMS, ATOFMS, and RSMS, and thermal vaporization followed by electron impact ionization for the AMS). Some were limited to particles with diameters in excess of $200 \mathrm{~nm}$, while the AMS and RSMS routinely detected particles down to about $50 \mathrm{~nm}$. (Particles smaller than the above referenced size limits sometimes may be analyzed, but only for special situations, e.g. specific particle compositions or very high particle concentrations in air.) The AMS is optimized to detect and classify organic material, whereas the laser desorption/ionization instruments are best for refractory material such as soot, sodium chloride, and dust. This comparison demonstrates the need for various types of instruments in order to obtain a complete picture of the aerosol chemical content.

One of the earliest portable instruments, developed by Murphy and co-workers, $[87,88]$ is designed to fit into the nose cone of an airplane, and can thus be used to monitor aerosol concen- 
tration and composition as a function of altitude and in the wake of aircraft or rockets.

\subsection{Data handling}

One of the problems in the deployment of field portable instruments is the volume of data collected. If an instrument collects single particle mass spectra at the rate of three per second for a period of 1 month, the number of stored spectra is close to 8 million. This provides a challenge for data storage, especially in the case of high resolution data. But an even greater problem involves data analysis. How can so much information be digested, and retrieved? The approach depends on the information desired. If changes in the concentrations of individual chemical components are the focus, then the signal intensities of specific marker ions for those components can be extracted from the data and interpreted [22,89,90]. More commonly, a neural network algorithm is used to sort large numbers of single particle spectra into a few particle classes having unique distributions of chemical components in the particle [91-94]. Articles by Zelenyuk et al. and Hinz et al. in this issue also address particle classification. Since the focus of this review is hardware rather than software, the interested reader should consult the above referenced articles for further information.

\section{Conclusion}

The field of aerosol mass spectrometry continues to develop. This review has discussed several approaches that allow for the detection and speciation of a wide range of particle sizes and compositions. However, much work remains in order to continue to expand the range of size and types of particles that any one instrument can analyze. Finally, the continued advancement of portable instruments has also been extremely important to the aerosol mass spectrometry field. Portable instruments have been integral in source apportionment studies as well in studies which aim to examine real time effects of changes in meteorological conditions on particle size and composition. Despite all of these advancements, real atmospheric particles are too complex for one instrument to optimally detect and quantify the composition of them all. Therefore, there is much room and need for the continued development of several different types of instruments.

\section{References}

[1] D.T. Seuss, K.A. Prather, Chem. Rev. 99 (1999) 3007.

[2] A.L. Hunt, G.A. Petrucci, Trends Anal. Chem. 21 (2002) 74.

[3] M.V. Johnston, J. Mass Spectrom. 35 (2000) 585.

[4] C.A. Noble, K.A. Prather, Mass Spectrom. Rev. 19 (2000) 248.

[5] D.M. Murphy, Science 307 (2005) 1888

[6] D.M. Murphy, Mass Spectrom. Rev., in press.

[7] W.D. Reents, Z. Ge, Aerosol Sci. Technol. 33 (2000) 122.

[8] B.J. Finlayson-Pitts, J.N. Pitts, Chemistry of the Upper and Lower Atmosphere: Theory, Experiments and Applications, Academic Press, New York, 2000.

[9] H.C. Van de Hulst, Light Scattering by Small Particles, Wiley Interscience, New York, 1957.

[10] J.W. Morris, P. Davidovits, J.T. Jayne, Q. Shi, C.E. Kolb, D.R. Worsnop, W.S. Barney, J. Jimenez, G.R. Cass, Geophys. Res. Lett. 29 (2002) 71.
[11] Y. Katrib, G. Biskos, P.R. Buseck, P. Davidovits, J.T. Jayne, M. Mochida, M.E. Wise, D.R. Worsnop, S.T. Martin, J. Phys. Chem. A 109 (2005) 10910.

[12] G.D. Smith, E. Woods III, C. Hauser, R.E. Miller, T. Baer, J. Phys. Chem. A 106 (2002) 8085.

[13] J.D. Hearn, G.D. Smith, J. Phys. Chem. A 108 (2004) 10019

[14] J.D. Hearn, G.D. Smith, Phys. Chem. Chem. Phys. 7 (2005) 2549.

[15] Y. Katrib, S.T. Martin, Y. Rudich, P. Davidovits, J.T. Jayne, D.R. Worsnop, Atmos. Chem. Phys. Discuss. 4 (2004) 6431.

[16] T.D. Saul, M.P. Tolocka, M.V. Johnston, J. Phys. Chem. A 110 (2006) 7614.

[17] M.P. Tolocka, T.D. Saul, M.V. Johnston, J. Phys. Chem. A 108 (2004) 2659.

[18] M.P. Tolocka, K.J. Heaton, M.A. Dreyfus, S.Y. Wang, C.A. Zordan, T.D. Saul, M.V. Johnston, Environ. Sci. Technol. 40 (2006) 1843.

[19] L.S. Hughes, J.O. Allen, P. Bhave, M.J. Kleeman, G.R. Cass, D. Y. Liu, D.P. Fergenson, B.D. Morrical, K.A. Prather, Environ. Sci. Technol. 34 (2000) 3058.

[20] S.A. Guazzotti, J.R. Whiteaker, D.T. Seuss, K. Coffee, K.A. Prather, Atmos. Environ. 25 (2001) 3229.

[21] D.J. Phares, K.P. Rhoads, M.V. Johnston, A.S. Wexler, J. Geophys. Res. 108 (2003) 8420.

[22] M.P. Tolocka, D.A. Lake, M.V. Johnston, A.S. Wexler, Atmos. Environ. 38 (2004) 3263.

[23] Q. Zhang, C.O. Stanier, M.R. Canagaratna, J.T. Jayne, D.R. Worsnop, S.N. Pandis, J.L. Jimenez, Environ. Sci. Technol. 38 (2004) 4797.

[24] J.N. Smith, K.F. Moore, F.L. Eisele, D. Voisin, A.K. Ghimire, H. Sakurai, P.H. McMurry, J. Geophys. Res. 110 (2005) D22S03.

[25] M.P. Tolocka, D.A. Lake, M.V. Johnston, A.S. Wexler, Atmos. Environ. 38 (2004) 3215.

[26] D.J. Cziczo, D.S. Thomson, D.M. Murphy, Science 291 (2001) 1772.

[27] D.M. Murphy, P.K. Hudson, D.S. Thomson, P.J. Sheridan, J.C. Wilson, Environ. Sci. Technol. 40 (2006) 3163.

[28] P. Liu, P.J. Ziemann, D.B. Kittelson, P.H. McMurry, Aerosol Sci. Technol. 22 (1995) 293.

[29] P. Liu, P.J. Ziemann, D.B. Kittelson, P.H. McMurry, Aerosol Sci. Technol. 22 (1995) 314.

[30] X. Wang, F.E. Kruis, P.H. McMurry, Aerosol Sci. Technol. 39 (2005) 611.

[31] X. Wang, A. Gidwani, S.L. Girshick, P.H. McMurry, Aerosol Sci. Technol. 39 (2005) 624.

[32] X. Wang, P.H. McMurry, Aerosol Sci. Technol. 40 (2006) 320.

[33] G.A. Petrucci, P.B. Fransworth, P. Cavelli, N. Omenetto, Aerosol Sci. Technol. 33 (2000) 105.

[34] Y. Su, M.F. Sipin, H. Furutani, K.A. Prather, Anal. Chem. 76 (2004) 712.

[35] A. Zelenyuk, D. Imre, Aerosol Sci. Technol. 39 (2005) 554.

[36] D.B. Kane, B. Oktem, M.V. Johnston, Aerosol Sci. Technol. 35 (2001) 990.

[37] S. Wang, C.A. Zordan, M.V. Johnston, Anal. Chem. 78 (2006) 1750.

[38] P.F. DeCarlo, J.G. Slowik, D.R. Worsnop, P. Davidovits, J.L. Jimenez, Aerosol Sci. Technol. 38 (2004) 1185.

[39] J.T. Jayne, D.C. Leard, X. Zhang, P. Davidovits, K.A. Smith, C.E. Kolb, D.R. Worsnop, Aerosol Sci. Technol. 33 (2000) 49.

[40] A. Zelenyuk, Y. Cai, D. Imre, Aerosol Sci. Technol. 40 (2006) 197.

[41] K.R. Wilson, A.N. Arrowsmith, M. Ahmed, S.R. Leone, Nanoletters 5 (2005) 1009.

[42] C.F. Bohren, D.R. Huffman, Absorption and Scattering of Light by Small Particles, Wiley Interscience, New York, 1983.

[43] A.K. Ray, A. Souyri, E.J. Davis, T.M. Allen, Appl. Opt. 30 (1991) 3974.

[44] K. Chamaillard, C. Kleefeld, S.G. Jennings, D. Ceburnis, C.D. O’Dowd, J. Quant. Spectrosc. Radiative Transfer 101 (2006) 498.

[45] Y. Pavlyukh, W. Hubner, Phys. Rev. B 70 (2004) 245434.

[46] K. Salt, C.A. Noble, K.A. Prather, Anal. Chem. 68 (1996) 230.

[47] E.R. Mysak, Y.N. Dessiaterik, C.J. McKinney, R.E. Miller, T. Baer, Rev. Sci. Instrum. 77 (2006) 013301.

[48] K.A. Prather, T. Nordmeyer, K. Salt, Anal. Chem. 66 (1994) 1403.

[49] B.A. Mansoori, M.V. Johnston, A.S. Wexler, Anal. Chem. 66 (1994) 3681.

[50] P.J. McKeown, M.V. Johnston, D.M. Murphy, Anal. Chem. 63 (1991) 2069.

[51] M.P. Sinha, Rev. Sci. Instrum. 55 (1984) 886.

[52] D.A. Lake, M.P. Tolocka, M.V. Johnston, A.S. Wexler, Environ. Sci. Technol. 37 (2003) 3268.

[53] P.G. Carson, M.V. Johnston, A.S. Wexler, Rapid Commun. Mass Spectrom. 12 (1998) 993. 
[54] F.W. McLafferty, F. Turecek, Interpretation of Mass Spectra, University Science Books, Sausalito, CA, 1993.

[55] P.J. Silva, K.A. Prather, Anal. Chem. 72 (2000) 3553.

[56] D.S. Gross, M.E. Galli, P.J. Silva, K.A. Prather, Anal. Chem. 72 (2000) 416.

[57] D.B. Kane, M.V. Johnston, Environ. Sci. Technol. 34 (2000) 4887.

[58] Y. Dessiaterik, T.G. Nguyen, R.E. Miller, T. Baer, J. Phys. Chem. A 107 (2003) 11249.

[59] E. Woods III, G.D. Smith, Y. Dessiaterik, T. Baer, R.E. Miller, Anal. Chem. 73 (2001) 2317.

[60] B. Oktem, M.P. Tolocka, M.V. Johnston, Anal. Chem. 76 (2004) 253.

[61] S.E. van Bramer, M.V. Johnston, Appl. Spectrosc. 46 (1991) 255.

[62] J.W. Hepburn, in: A.B. Myers, T.R. Rizzo (Eds.), Laser Techniques in Chemistry, John Wiley and Sons Inc., New York, 1995, p. 149.

[63] D.G. Nash, X.F. Liu, E.R. Mysak, T. Baer, Int. J. Mass Spectrom. 241 (2005) 89.

[64] J. Sugar, A. Musgrove, J. Phys. Chem. Ref. Data 20 (1991) 859.

[65] E.R. Mysak, K.R. Wilson, M. Jimenez-Cruz, M. Ahmed, T. Baer, Anal. Chem. 77 (2005) 5953.

[66] M.P. Tolocka, K.J. Heaton, M.A. Dreyfus, S. Wang, C.A. Zordan, T.D. Saul, M.V. Johnston, Environ. Sci. Technol. 40 (2006) 1843.

[67] H.J. Tobias, P.J. Ziemann, Environ. Sci. Technol. 34 (2000) 2105.

[68] W.D. Reents, M. Schabel, Anal. Chem. 73 (2001) 5403.

[69] R. Mahadevan, D. Lee, H. Sakurai, M.R. Zachariah, J. Phys. Chem. A 106 (2002) 11083.

[70] D. Lee, K. Park, M.R. Zachariah, Aerosol Sci. Technol. 39 (2005) 162.

[71] A. Cappiello, G. Famiglini, A. Lombardozzi, A. Massari, G.G. Vadalia, J. Am. Soc. Mass Spectrom. 7 (1996) 753.

[72] H.J. Leis, G. Fauler, G.N. Rechberger, W. Windischhofer, Curr. Med. Chem. 11 (2004) 1585.

[73] B.W. LaFranchi, G.A. Petrucci, J. Am. Soc. Mass Spectrom. 15 (2004) 424.

[74] B.W. LaFranchi, J. Zahardis, G.A. Petrucci, Rapid Commun. Mass Spectrom. 18 (2004) 2517.

[75] H.J. Tobias, P.J. Ziemann, Anal. Chem. 71 (1999) 3428.

[76] H.J. Tobias, P.M. Kooiman, K.S. Docherty, P.J. Ziemann, Aerosol Sci. Technol. 33 (2000) 170.

[77] J.D. Hearn, G.D. Smith, Anal. Chem. 76 (2004) 2820.
[78] A.C. Lazar, P.T.A. Reilly, W.B. Whitten, J.M. Ramsey, Anal. Chem. 72 (2000) 2142.

[79] D. Voisin, J.N. Smith, H. Sakurai, P.H. McMurry, F.L. Eisele, Aerosol Sci. Technol. 37 (2003) 417.

[80] J.N. Smith, K.F. Moore, P.H. McMurry, F.L. Eisele, Aerosol Sci. Technol 32 (2004) 100.

[81] E. Gard, J.E. Mayer, B.D. Morrical, T. Dienes, D.P. Fergenson, K.A. Prather, Anal. Chem. 69 (1997) 4083.

[82] M. Yang, P.T.A. Reilly, K.B. Boraas, W.B. Whitten, J.M. Ramsey, Rapid Commun. Mass Spectrom. 10 (1996) 347.

[83] P.T.A. Reilly, R.A. Gieray, W.B. Whitten, J.M. Ramsey, Environ. Sci. Technol. 32 (1998) 2672.

[84] F. Drewnick, S.S. Hings, P.F. DeCarlo, J.T. Jayne, M. Gonin, K. Fuhrer, S. Weimer, J. Jimenez, K.L. Demerjian, S. Borrmann, D.R. Worsnop, Aerosol Sci. Technol. 39 (2005) 637.

[85] A.M. Middlebrook, D.M. Murphy, S.-H. Lee, D.S. Thompson, K.A. Prather, R.J. Wenzel, D.-Y. Liu, D.J. Phares, K.P. Rhoads, A.S. Wexler, M.V. Johnston, J.L. Jimenez, J.T. Jayne, D.R. Worsnop, I. Yourshaw, J.H. Seinfeld, R.C. Flagan, J. Geophys. Res. 108 (2003) 12, SOS.

[86] M. Jaoui, K.G. Sexton, R.M. Kamens, Atmos. Environ. 38 (2004) 2709.

[87] D.J. Cziczo, D.M. Murphy, D.S. Thomson, M.N. Ross, Geophys. Res. Lett. 29 (2002) 33.

[88] D.S. Thompson, M.E. Schein, D.M. Murphy, J. Aerosol Sci. 33 (2000) 153.

[89] E. Gard, M.J. Kleeman, D.S. Gross, L.S. Hughes, J.O. Allen, B.D. Morrical, D.P. Fergenson, T. Dienes, M.E. Galli, R.J. Johnson, G.R. Cass, K.A. Prather, Science 279 (1998) 1184.

[90] Q. Zhang, M.R. Alfarra, D.R. Worsnop, J.D. Allan, H. Coe, M.R. Canagaratna, J.L. Jimenez, Environ. Sci. Technol. 39 (2005) 4938.

[91] D.P. Fergenson, D.Y. Liu, P.J. Silva, K.A. Prather, Chemom. Intell. Lab. Syst. 37 (1997) 197.

[92] D.J. Phares, K.P. Rhoads, A.S. Wexler, D.B. Kane, M.V. Johnston, Anal. Chem. 73 (2001) 2338

[93] K.-P. Hinz, M. Greweling, F. Drews, B. Spengler, J. Am. Soc. Mass Spectrom. 10 (1999) 648

[94] X.H. Song, P.K. Hopke, D.P. Fergenson, K.A. Prather, Anal. Chem. 71 (1999) 860

[95] W.C. Hinds, Aerosol Technology: Properties, Behavior and Measurement of Airborne Particles, Wiley Interscience, New York, 1982. 